\title{
MULHERES ESTUDANTES CRIANDO SEUS FILHOS NO CONTEXTO DA FAMÍLIA MONOPARENTAL
}

\author{
STUDENT WOMEN CREATING HER CHILDREN \\ IN THE CONTEXT OF A ONE-PARENT FAMILY \\ MUJERES ESTUDIANTES CREANDO SUS HIJOS \\ EN EL CONTEXTO DE FAMILIA MONOPARENTAL
}

Cristiane Jackson Borges*

Maira Buss Thofehrn**

Sonia Maria K. Meincke***

* Acadêmica de Enfermagem Autora do Trabalho Monográfico.

** Doutora em Enfermagem, Professora Adjunta da Faculdade de Enfermagem e Obstetrícia da Universidade Federal de Pelotas, Orientadora do Trabalho e Coordenadora do NEPEN.

*** Enfermeira, Professora Assistente da Faculdade de Enfermagem e Obstetrícia da UFPel. Doutoranda do programa de Pós-Graduação da UFSC.

RESUMO. Este trabalho teve por objetivo conhecer as dificuldades enfrentadas por mulheres estudantes de enfermagem para criar seus filhos sem a presença paterna. Foi utilizada uma abordagem qualitativa, descritiva e exploratória. Os dados foram coletados através em entrevistas semi-estruturadas. Os sujeitos deste estudo constituiram-se de três acadêmicas de enfermagem de uma universidade da Região Sul do Rio Grande do Sul. Os resultados foram reunidos em quatro temas: (a) Dividida e multiplicada: a "supermãe" atual. (b) Mãe por destino, cuidadora por opção. (c) O porque cuidar do cuidador. (d) Ensinar é dar consistência às palavras pelo exemplo. O estudo possibilitou uma aproximação com a realidade vivida por essas mães estudantes, indicando que elas se sentem sobrecarregadas pelos múltiplos papéis desempenhados: mãe, dona-de-casa e estudante. Observou-se que o currículo desta instituição tem pouca flexibilidade, dificultando o processo de viver dessas acadêmicas.

PALAVRAS-CHAVE: mulheres estudantes; enfermagem; famílias monoparentais.

ABSTRACT. This work had for objective to know the difficulties faced for mothers nursing students, in creating her children without paternal presence. A qualitative, descriptive and exploratory boarding was used. The data had been collected through halfstructuralized interview. The citizens that had served for base in this study consisted of three nursing academics in the South Region of Rio Grande do Sul's university. The results had been congregated in four subjects: (a) Divided and multiplied: the current "supermother". (b) Mother for destination, who takes care for option. (c) The reason to take care of who normally takes care. (d) To teach is to give consistence to the words showing the example. The study made possible an approach with the reality lived by these mothers students, indicating that the they are felt overloaded by the multiple played roles: mother, owner-of-house and student. It was observed that the resume of this institution possesses little flexibility for the students, becoming difficult to the nursing academics live in this new and increasing situation.

KEYWORDS: student women; nursing; one parent family.

RESUMEN. Esta investigación tiene como finalidad conocer las dificultades que enfrentan las mujeres que estudian enfermería al criar sus hijos sin la presencia paterna. El abordaje utilizado fue cualitativo descriptivo y explorador. Los datos se colectaron por medio de entrevista semiestructurada. La muestra del estudio fue formada por tres estudiantes de enfermería de una Universidad de la región sur de la Provincia de Rio Grande do Sul. Los resultados fueron clasificados en cuatro temas: (a) Dividida y multiplicada: la "súpermadre" actual. (b) Madre por destino, cuidadora por opción. (c) El porquê del cuidar del cuidador. (d) Enseñar y dar respaldo a las palabras a través del ejemplo. El estudio permitió una aproximación con la realidad vivida por estas madres estudiantes, mostrando que ellas se sienten extenuadas por los múltiplos papeles que desenvuelven: madre, dueña de casa y estudiante. Se observó que el currículo de la universidad es poco flexible, dificultando la forma de vivir de estas universitarias de Enfermería.

PALABRAS-CLAVE: mujeres estudiantes; enfermería; familias monoparentales.

Recebido em: 03/06/2004

Aceito em: 11/12/2004
Maira Buss Thofehrn

R. Carlos Gomes, 541

9655-450 - Pelotas - RS

Fone: (53) 3273-3116 - E-mail: mairabt@ufpel.tche.br 


\section{INTRODUÇÃO}

A família é uma entidade histórica, mutável na medida em que muda a própria história através dos tempos e se confunde com a história da própria humanidade ${ }^{1}$. Mais especificamente a família é a célula mãe da sociedade, do seu núcleo inicial e regular, do seu microssistema social; os valores de uma época são repassados de modo a garantir uma adequada formação da pessoa, com vista a integrarse no ambiente social, para que encontre amparo irrestrito e, assim, a sua própria felicidade ${ }^{2}$.

A família surgiu no período paleolítico, em virtude de a mulher estimular o sedentarismo, através da agricultura, rompendo com o modo de vida nômade. Com o aumento da população, em determinada área territorial, estimulou nos homens a disputa pela melhor caça e melhor agricultura, determinando o surgimento das guerras e, conseqüentemente, dos heróis. Os vencedores apossavam-se das terras, dominando as mulheres pela força física; assim, entraram para o rol de pertences do homem. Quanto mais mulheres um homem tivesse, maior número de filhos e maior poder ele teria sobre os demais ${ }^{3}$.

O tempo passou e a família sofreu transformações ao longo da história da humanidade; hoje as mulheres continuam a alimentar, criar e educar os filhos, princípios básicos já presentes desde a formação da família. Atualmente, as mulheres também se inserem no processo de prover a subsistência da família. Nas últimas três décadas, a tradicional divisão de papéis entre homens e mulheres sofreu grandes alterações. Hoje, ambos já não recebem uma educação formal tão diferenciada. As mulheres pleiteiam as mesmas faculdades e ocupam espaços cada vez maiores no mercado de trabalho ${ }^{3}$.

A família tradicional está deixando de ser padrão, dando lugar a famílias monoparentais: é a entidade familiar, em que o lar está sob responsabilidade de um só genitor que pode ser solteiro, viúvo, separado ou divorciado e seus filhos ${ }^{4}$. Assim, essa organização familiar é formada por qualquer um dos pais e seus descendentes. O termo família monoparental só foi reconhecido no Direito Brasileiro, em 1988, com a promulgação da Constituição Federal ${ }^{5}$.

Em face das questões apresentadas, nesse estudo ao utilizar o termo família monoparental me reporto a genitora, à mãe que, sozinha, cria seus filhos. Aquela mulher que assume o comando do lar, está inserta no mercado de trabalho, freqüenta universidades no intuito de melhorar a sua qualidade de vida e ter oportunidades de crescer profissionalmente,sem deixar de ser mãe.

O grande número de famílias sem pai é motivo de preocupação social, porque as mulheres sem cônjuge e seus filhos estão sujeitos a sofrer tensão emocional, dificuldades financeiras e desvantagens sociais. Na ausência do homem, a mulher está assumindo o comando do lar, o que tem determinado, freqüentemente, um esfacelamento da família ${ }^{6}$.

Em pesquisas recentes, tem-se apontado que no Brasil o número de mulheres chefes de domicílio tem aumentado nas últimas décadas, especialmente nas áreas urbanas. O aumento da pobreza e as dificuldades de sobrevivência nas cidades têm gerado arranjos familiares alternativos, em que papel das mulheres é prioritário no sustento da casa e na criação dos filhos. No entanto, ao contrário do que é comumente apontado pelo senso comum e pela mídia, esse não é fenômeno recente. Inúmeros trabalhos, com ênfase no papel social das mulheres, durante o período colonial brasileiro, demonstraram que existia um número considerável de mulheres chefiando domicílios, sendo este muitas vezes maior do que nos índices contemporâneos. Tendo esse aspecto em mente, a característica de mulher do século XXI está além do comando da casa, de chefiar seu lar, pois cada vez mais ela está mudando e tem também de buscar crescimento, realização pessoal, ascensão e aprimoramento profissional 7 .

Durante minha trajetória acadêmica na área de saúde, vivenciei diversas dificuldades relacionadas à estruturação familiar. Apesar de ser casada, tive de assumir a casa, filhos, faculdade, pagar contas e ter 
muitas responsabilidades e equilíbrio para criar meus filhos, pois meu marido reside em outra cidade. Desta forma, classifico-me como responsável por uma família monoparental.

Pela experiência vivenciada, percebo que ser mãe não é fácil, especialmente sem a presença paterna no cotidiano, para auxiliar desde as atividades relacionadas aos cuidados físico-biológicos até os afetivo-comportamentais. Assim, é possível imaginar o grau de dificuldades que enfrentam as estudantes de enfermagem que além, de estudantes, também têm filho para criar. Para sua formação acadêmica é preciso lidar com o sofrimento, a doença, a vida e a morte, prestando cuidado terapêutico que visa criar vínculos com as pessoas enfermas. O cuidado terapêutico consiste na atividade propriamente dita do trabalho da enfermagem, ou seja, é a tarefa profissional, uma ação e um discurso com intenção terapêutica, para resolução dos problemas de saúde das pessoas, tanto no âmbito preventivo e curativo, quanto na reabilitação, um agir com competência profissional que direcione o ser humano e a comunidade a uma vida saudável ${ }^{8}$. Esse cuidado tem sua ênfase, tanto na habilidade técnica, quanto emocional, o que acarreta envolvimento e comprometimento maior com a outra pessoa. Essa contínua e elevada carga emocional, em muitos casos, tem abalado a qualidade de vida dessas futuras profissionais. Além disso, elas têm a responsabilidade de criar seus filhos, exercendo o papel de mãe cuidadora e de pai provedor.

A partir de reflexões sobre esta problemática é que me motivei a realizar estudo cujo objetivo é identificar as dificuldades enfrentadas por mulheres, estudantes de enfermagem, que criam seus filhos sem a presença paterna.

Diante dos resultados obtidos, espero poder contribuir com a temática em tela, propondo assistência a essas mulheres por parte das instituições formadoras, para elas passarem a ter melhor qualidade de vida. Almejo também instigar a reflexão quanto "ao ser mulher pós queima dos sutiãs" e a conseqüente desorganização dos papéis sociais, tentando construir novos paradigmas, uma visão de mundo em que a sociedade dê respaldo às necessidades da mulher atual.

\section{METODOLOGIA}

Esse estudo tem abordagem qualitativa do tipo exploratório e descritivo. A pesquisa foi realizada em universidade da Região Sul do Rio Grande do Sul, no período de setembro a novembro de 2005. Fizeram parte da pesquisa três alunas, regularmente matriculadas em Curso de Enfermagem e que atenderam aos seguintes critérios: ter um ou mais filhos; estar criando filhos sem a presença paterna no cotidiano familiar; serem maiores de 18 anos; aceitarem o uso de gravador durante a entrevista; manifestarem interesse em participar do estudo; permitirem a divulgação dos dados coletados. As acadêmicas foram identificadas mediante codificação de nomes de cantoras brasileiras, a seu critério de escolha, para lhes assegurar o anonimato: (a) Cássia Eller, trinta anos, dois filhos e renda oriunda de pensão alimentícia; (b) Paula Toller vinte e nove anos, dois filhos; (c) Rita Lee vinte e oito anos, um filho, as duas últimas com renda originalmente do salário do marido.

Os princípios éticos se fizeram presentes durante todo o transcorrer da pesquisa, com atenção especial aos critérios contidos no Código de Ética dos Profissionais de Enfermagem ${ }^{9}$. Ficou assegurada a possibilidade de desistência em qualquer momento da pesquisa e o livre acesso aos dados coletados, sem que isso causasse qualquer prejuízo à pessoa, além de cumprir o preconizado na Resolução n. ${ }^{\circ}$ 196/96 do Conselho Nacional de Saúde ${ }^{10}$, que dispõe sobre pesquisa com seres humanos, assegurando a proteção dos grupos vulneráveis e autonomia dos sujeitos. A proposta do estudo foi aprovada pelo Comitê de Ética da instituição. Após a seleção dos sujeitos, foi exposto o objetivo do trabalho, realizado o convite para participar do estudo e, após aceite, foi assinado o termo de Consentimento Livre e Esclarecido. 
Para a coleta de dados foram utilizadas uma entrevistas semi-estruturadas. As entrevistas foram gravadas e transcritas na íntegra. Após ler e reler várias vezes os dados coletados e confrontá-los com a bibliografia consultada e o posicionamento da autora, as respostas foram agrupadas e classificadas por temas, resultando em: (a) dividida e multiplicada, a supermãe atual; (b) mãe por destino, cuidadora por opção; (c) o cuidar da cuidadora; (d) ensinar é dar consistência às palavras pelo exemplo.

\section{APRESENTAÇÃO E ANÁLISE DOS DADOS}

a) Dividida e Multiplicada: a Supermãe Atual

Esse tema traduz a angústia e o estresse da mãe, mulher cuidadora sentindo-se sobrecarregada com os múltiplos papéis desempenhados no seu cotidiano. Ao abordar as funções da mulher na atualidade observa-se que elas desempenham papéis múltiplos e conflitantes, pois de um lado elas acreditam no fato de que têm direito a uma vida própria, a um emprego e profissão e, de outro, continuam a acreditar que a mãe é indispensável para a boa formação dos filhos, não importando que soluções tenham encontrado para conciliar estas duas necessidades. Assim divididas e multiplicadas estas mulheres estão cheias de culpa por não estarem realizando o que acreditam que deveriam fazer no campo profissional e por não estarem alcançando a excelência que almejam no plano familiar. Além disso, elas estão submetidas a uma sobrecarga física, que torna o seu viver difícil de ser suportado ${ }^{11}$.

Nas entrevistas percebe-se o reconhecimento dos sujeitos quanto à complexidade de ser mãe, mulher e cuidadora, a atualidade, onde a mulher se insere num novo contexto de família, em que os filhos são criados e educados pela mãe e com pouca intervenção paterna. Elas relatam que:

O apoio que ele dá é o financeiro e deu; então tem toda a sobrecarga, a começar a lidar com o ser mãe e ser pai, então tem que preencher não só a tua lacuna que já não consegue, ainda tem que suprir a necessidade de pai, pai ausente, afazeres dos filhos, esse apoio ele dava, isso foi tirado, então teve mais essa sobrecarga por tentar ser mãe e pai tudo junto, que na verdade não se consegue fazer, agente tenta!!! (Cássia Eller)

Em primeiro lugar é a dificuldade de conseguir estudar, sabe de tu conciliar, ter prova, chegar em casa tem que estudar, como que tu vai estudar com duas crianças pequenas em casa [...] é difícil de conseguir estudar com eles junto [...] durante a semana tu és estudante e mãe e no final de semana tu és mulher, mãe, dona de casa e estudante, nunca pode esquecer. Eu me sinto sobrecarregada, tinha noites que eu não dormia e no outro dia, levantar e ir ao estágio curricular. (Paula Toller)

Acho que a maior dificuldade foi o peso da responsabilidade, pois tive que assumir tudo sozinha, casa, filhos e faculdade e não tinha com quem dividir esse peso, por muitas vezes me senti exausta, muito cansada, sobrecarregada e com vontade de desistir de tudo, ficar em casa criando e educando meu filho, pois achei que seria impossível conciliar os estudos com a responsabilidade de ser mãe. (Rita Lee)

O foco da vida da mulher, antes voltado para o outro, para a satisfação das necessidades daqueles à sua volta, ao buscar o estudo fora de casa esse foco desloca-se, então, para seu crescimento e desenvolvimento integral como ser humano. Esta nova ênfase no crescimento pessoal acarretou uma série de mudanças sociais que levaram à necessidade de um planejamento de vida individualizado. Apesar de todas essas mudanças, o que se pode observar é que a "nova" identidade atribuída à mulher apenas se ampliou para incluir, também seus novos interesses com a carreira e com a profissão ${ }^{11}$.

Essa idéia é reforçada ao mencionar que, na década de 60, a mulher se emancipou e ganhou destaque socioeconômico, profissional e cultural, mas na grande maioria o instinto materno, a inclinação para ocupar-se da perpetuação da espécie, ainda fala mais alto que todas as suas conquistas. Em virtude desse instinto é que, ainda hoje, as mulheres se sentem culpadas por ficar longe dos filhos e ao voltar para casa e tirar o uniforme social (símbolo de sua ausência), para vestir o de dona-de-casa (símbolo da sua presença), o instinto materno alimenta a culpa 
feminina de ter estado ausente. Essa mãe tem sempre a impressão de contrariar o instinto materno ${ }^{3}$.

Quando as três mães relatam sentirem-se sobrecarregadas pelos múltiplos papéis desempenhados no seu cotidiano, identifiquei a presença do sentimento de angústia, que é um tipo de tensão que surge sempre que a pessoa enfrenta uma situação em que um obstáculo impede a realização de seu objetivo e satisfação de suas necessidades. A tensão excessiva pode ser prejudicial para a aprendizagem e para outros aspectos do comportamento humano, e por consumir energia, a excessiva tensão pode facilmente provocar uma exaustão nervosa permanente ${ }^{12}$.

A tensão gerada pela sobrecarga dos múltiplos papéis que as mulheres estão desempenhando nas últimas décadas tem reflexos prejudiciais no ambiente familiar, profissional e sobretudo no seu lado emocional, elas se sentem desamparadas de todas as formas; a mulher atual desempenha o seu papel e o papel do homem perante a sociedade, mas não estava preparada para exercer essa nova identidade de mãe, mulher e profissional.

No século passado o simples fato de a pessoa estar ausente do lar, manter materialmente as necessidades dos filhos era suficiente no âmbito judicial. Atualmente, a justiça já está levando em consideração os danos psicológicos e emocionais causados nos filhos em decorrência da ausência, no caso desse estudo, ausência do pai. Por outro lado, as tensões identificadas na mãe, estudante de enfermagem, também interferem no processo de viver dos filhos.

A ausência do pai, física, psicológica, econômica ou social, produzirá repercussões sobre o universo psicológico do filho, pois esta ausência é como a falta de uma estrutura interna. "Faltar o pai é faltar a coluna vertebral. [...] A identidade psicológica de um indivíduo baseia-se em um sentimento de ter uma coluna vertebral e de sentir-se sustentado em seu interior" 13:45. Assim, as tensões identificadas na mãe estudante de enfermagem, são acrescidas das intercorrências que essa ausência do pai desencadeia em seus filhos, o que interfere no seu processo de ser e viver saudável.

b) Mãe por destino, cuidadora por opção

Mãe por destino entende-se como uma circunstância, direção, rumo na trajetória de vida das mulheres deste estudo. Cuidadora por opção referese ao fato de as mulheres terem escolhido cuidar de seus filhos, mesmo sem a presença do pai. Cuidar é mais que um ato; é uma atitude; portanto abrange mais que um momento de atenção, de zelo e desvelo representa uma atitude de ocupação, preocupação, responsabilidade e envolvimento afetivo com o outro ${ }^{14}$.

Cuidar da família, dos filhos, da casa e dos empregados era função da mulher que estava restrita a exercer funções dentro do lar.

O profissional de saúde é um cuidador sob constante tensão. Seu objeto de trabalho é a pessoa doente, alguém atingido na integridade física, psíquica e social, vulnerável na sua auto-estima; alguém que expressa sofrimento, muitas vezes exteriorizando sinais e sintomas difíceis de suportar, exigindo dos profissionais de saúde resultados, acima de suas possibilidades humanas de alcançá-los. Não é difícil antever que tais profissionais são, muitas vezes, pessoas estressadas, impotentes, sobrecarregadas, despreparadas, culpadas, revoltadas, isoladas e desamparadas, especialmente, em momentos de angústia ${ }^{15}$.

Os aspectos apontados pelos autores são nitidamente averiguados

Uma coisa é tu ser cuidadora com suporte afetivo ter alguém do teu lado, e suporte financeiro, ainda assim a mulher tem aquela sobrecarga de cuidadora, cuidar do lar, cuidar dos filhos, cuidar do marido, e tem o outro lado, outra coisa é tu ser cuidadora sem suporte, a carga é muito maior, tu não tem apoio emocional do marido e não tem apoio da sociedade, a sociedade na verdade não quer saber se tu tens filhos, se tu és sozinha, "te ferra !!!" Escutei uma frase que nunca mais eu esqueci: "quem mandou tu querer ser mãe primeiro pra depois querer virar gente!!!" (Cássia Eller) 
Tu quer às vezes um abraço amigo, uma palavra, uma humanização, realmente como é pregado na faculdade que não seja aquilo da boca pra fora, que tu tens que ter com o paciente, mas ninguém tem contigo, mas no momento que um professor se prontifica a te ajudar tu sabe, bá é assim que eu devo tratar meu paciente, que legal!!! (Paula Toller)

Muitas vezes eu me questionava quando estava no hospital atendendo um paciente, será que o certo não seria eu estar em casa cuidando do meu filho ao invés de estar aqui? Acho que tudo reflete no teu desempenho, seja como acadêmico ou profissional, não acredito que as pessoas não fiquem abaladas, emocionalmente e, que isso não vá se refletir no trabalho, se a gente não está bem por problemas pessoais é visível; nunca deixei de prestar um cuidado adequado aos pacientes. (Rita Lee)

No exercício do cuidado, o enfermeiro está exposto ao risco de cuidar do outro e ignorar suas próprias necessidades, não estando consciente da necessidade de cuidar de si, porque gasta toda a sua energia no cuidado do outro ${ }^{16}$. É relevante para os profissionais de enfermagem procurar melhorar a qualidade dos seus relacionamentos, pois o ambiente de trabalho está repleto de surpresas e expectativas, além do fato, de estes profissionais estarem em contato com seres vulneráveis, o que os torna também vulneráveis ${ }^{17}$.

Acredito que existe um equívoco em pensar que, por sermos mulheres, somos todas cuidadoras. Um aspecto é cuidar de um filho, outro é cuidar de um ser humano em sofrimento, em desequilíbrio biológico, psíquico e social e atendê-lo em suas necessidades, ou seja, dar banho, trocar fralda, fazer higienização oral, limpar feridas e escutar lamentos de dor e até mesmo presenciar sua morte no leito. Poderíamos ter escolhido qualquer outra profissão, em que não tivéssemos de lidar diariamente com o sofrimento humano, mas por opção escolhemos a enfermagem; portanto precisamos de apoio para aliviar as tensões geradas diariamente e assim continuar a jornada.

c) Desejando ser cuidado

O cuidado na enfermagem costuma ter como referência apenas a assistência prestada ao paciente.
Os profissionais acabam esquecendo o cuidado de si próprio e dos demais profissionais com os quais convivem, pois dificilmente nos permitimos ser também humanos, dotado de um corpo, mente e espírito que podem padecer de dor, desconforto e de sofrimento.

Cuidar, cuidando de si e deixando-se cuidar, identifica os enfermeiros com a lamparinasímbolo da Enfermagem que também irradia calor e luz. A lamparina, contudo, apresenta um reservatório para reabastecimento, o que pode ser traduzido num cuidar dos outros sem se consumir, cuidando de si mesmo 16:110.

O desejo de cuidar-ser-cuidado é indissociável. O desejo de cuidar de si (ser autônomo) passa pela necessidade de ser cuidado (depender) ${ }^{15}$. Ao mesmo tempo, tal necessidade precisa encontrar alguém que deseje ser cuidador. Nas falas dos sujeitos, que exponho a seguir, percebi a complexidade que envolve a questão do cuidar: o cuidar de si; do outro, enquanto, familiar, no caso deste estudo os filhos; o cuidar do outro em desequilíbrio de suas funções vitais, um cuidado profissional/terapêutico. Neste processo o cuidar de si começa:

A partir do momento que tu foi mãe, tu não tem mais que ser cuidada, tu tem que cuidar, cuidar de ti, dos teus filhos e dar conta de tudo, e cuidar da tua faculdade [...] uma carga muito maior, é redobrada, a mulher é cuidadora por excelência, tu já é intitulada cuidadora, só que tem que ter quem te cuide também, eu não me sinto cuidada, mas é a vida. (Cássia Eller)

O cuidado do outro é referido como uma necessidade de cuidar e ser cuidado:

Meu filho precisava de cuidados específicos e lá no hospital (estágio curricular) ficava pensando no que poderia acontecer em casa, tu fica com a tua cabeça a mil por hora, e teus colegas te olhando de cara feia, e nenhum professor chega pra ti e pergunta se tu precisa de ajuda, se tá tudo bem? [...] Muitas vezes é uma palavra amiga que eles te dêem é a força que tu precisa. (Paula Toller)

Confesso que muitas vezes não tinha ânimo nenhum para os estágios, e ainda te cobram pontualidade, freqüência, uniforme impecável e humanização no 
cuidado, só que esquecem que tu não és uma máquina e sim um ser humano que muitas vezes está precisando de cuidados também, eu me sinto desamparada. (Rita Lee)

O cuidador, ao atuar na enfermagem é um ser humano inserido numa organização de prestação de cuidados, é responsável por um atendimento de qualidade. Em conseqüência, ele tem de ser cuidado, para prestar um cuidado de excelência. Os profissionais de saúde, especialmente os de enfermagem, não podem limitar sua atenção ao atendimento daquilo que é visível no corpo. Ampliar esta visão é necessidade e forma de cuidar do cuidador, já que as situações de vida-morte sempre tão próximas do enfermeiro e da estudante de enfermagem; portanto, é preciso oferecer aos profissionais de saúde, principalmente os de enfermagem, subsídios para que compreendam aquilo que não se apresenta de forma visível aos olhos ${ }^{15}$.

Uma das formas de se cuidar é pelo desenvolvimento da competência interpessoal, ou seja, pela compreensão do processo de interação, que ocorre permanentemente entre as pessoas. A interação ocorre mediante comportamentos manifestos e não-manifestos, verbais e não-verbais, sentimentos e pensamentos, além da necessidade de aprimorar a autoconscientização e auto-aceitação, para entender as situações e informações com o mínimo de distorções. A competência interpessoal não é dom e sim uma capacidade a ser desenvolvida por meio da contínua percepção da pessoa em relação a si mesmo e aos outros ${ }^{18}$.

Como fator que poderia auxiliar essas mulheres mães e acadêmicas, duas entrevistadas citaram a possibilidade da criação de uma creche junto à universidade; assim o serviço ofereceria suporte e o apoio emocional para essas mães, pois:

Acho que a universidade poderia dar um apoio maior pra mãe mulher cuidadora, com a criação de uma creche,onde a criança teria um suporte psicológico ali dentro. É muito importante pra criança e também, porque se eu sou mãe, mulher, já adulta,sofro esse impacto, eles sofrem muito mais., Seria uma forma de ter suporte, tanto físico, quanto psicológico pra criança e pra mim como mãe; sabendo que meu filho está bem cuidado eu vou cuidar melhor do outro. (Cássia Eller)

Faz falta ter uma creche aqui para os filhos de professores e filhos dos alunos, pra todo mundo poder trabalhar e estudar tranqüilo. (Paula Toller)

d) Sentindo falta de apoio.

Acredito que, só podemos oferecer à nossa clientela aquilo que nos foi dado na família, na escola e na sociedade; portanto o cuidador, antes de qualquer coisa, deve ser cuidado, pois só assim terá estrutura emocional para prestar o cuidado. $\mathrm{Na}$ Enfermagem há o enfoque da humanização do cuidado, mas observa-se que este cuidado humanizado nem sempre é efetivado pelos profissionais, quer com a sua clientela, quer com seus alunos, pois:

Falta de apoio da universidade, ninguém quer saber se tu não tem com quem deixar o teu filho, tu és seqüestrada na verdade por um currículo, que te exige carga horária imensa, pouquíssimo tempo livre e o pouco tempo livre te sobrecarregam de afazeres, tu não é vista como um ser humano que tem dificuldades, na verdade passam uma mensagem de humanização, muito bonita pra ti, humanização no atendimento e no cuidado, só que tu não é cuidada com humanização, tu não é vista como ser humano ali dentro, tu é vista como acadêmico cumpridor de ordens, horários, trabalhos sem verem teu lado emocional. (Cássia Eller)

O professor tem que exercer o cuidado de enfermagem também com o aluno dele, o aluno ia render muito mais, tanto na teoria, quanto na prática, fundamentalmente tratar melhor o paciente no hospital se ele tiver o mesmo tratamento, agora ser tratado de baixo dos cascos e depois ter que tratar bem o teu paciente tu não sabe como agir, porque o exemplo que tu tens é o teu professor. [...] Tinha até professores que se preocupam, mas a maioria esse cuidado de enfermagem, a humanização é da boca pra fora, eles querem que a gente tenha com o paciente, mas eles não tem isso com a gente. (Paula Toller)

Na faculdade ocorreram fatos que me decepcionaram muito, na condição de acadêmica de enfermagem 
presenciei inúmeras vezes os professores dando um exemplo contrário ao cuidado humanizado tão ressaltado durante as aulas teóricas. (Rita Lee)

A universidade precisa adequar-se às necessidades da atual sociedade e realizar sua missão de conservação, comunicação e enriquecimento do patrimônio cultural, sem o qual nos tornaríamos meras máquinas de produção e consumo. Recomenda-se uma reforma da universidade, que leve em consideração a aptidão do ser humano para organizar o conhecimento e o pensar ${ }^{19}$.

O professor que realmente ensina, quer dizer, que trabalha os conteúdos diante do rigor do pensar, não admite a fórmula farisaica do "faça o que mando e não o que eu faço". Quem pensar certo sabe que as palavras, sem a corporeidade do exemplo pouco ou nada valem, pois pensar certo é fazer certo. Portanto a responsabilidade do professor é muito grande, às vezes não nos damos conta, pois a natureza eminentemente formadora, prioriza a maneira como realiza o ensino. Sua presença na sala de aula é de tal maneira exemplar que nenhum professor escapa ao juízo que dele fazem os alunos. E o pior talvez dos juízos é o que se expressa na "falta" de juízo ${ }^{20}$.

Pudemos observar, neste estudo, que o aluno, muitas vezes, está na condição de "paciente" necessitando de cuidados. O cuidado humanizado contempla compaixão ao próximo e pode ser aplicado não só no relacionamento enfermeiro/paciente, mas serve também de base no relacionamento professor/ aluno. Basta trocar a palavra enfermeiro por professor e paciente por aluno, respectivamente, que as palavras tomariam forma através do exemplo dado pelos professores. O cuidado humano surge de um interesse, uma preocupação, uma atenção, uma responsabilidade, além do afeto, do conforto e demais ações que levem ao bem-estar, à recuperação do corpo, da alma e da dignidade, implicando em ajudar a outra pessoa a crescer ${ }^{21}$.
Identificou-se que uma das entrevistadas, apesar de anteriormente criticar certas atitudes dos professores, deixa emergir uma reflexão quanto à possibilidade de apoio emocional, tanto para acadêmicos, quanto para os docentes formadores de cuidadores, pois ambos são merecedores de cuidados:

Mas não julgo, pois eles também têm seus problemas para resolver, eu só acho que cursos como o de enfermagem deveriam ter uma forma de apoio emocional tanto para acadêmicos, como para quem está formando cuidadores. (Rita Lee)

O que não podemos esquecer, quanto a certas atitudes dos professores para com os alunos, é que ser professor é ser profissional do ensino; mas os profissionais, além disso, são pessoas que possuem vida própria, repleta de tarefas, conflitos, sentimentos, papéis a desempenhar em seu cotidiano. Um professor pode ser sempre professor na sua identificação profissional, o que não significa que esteja funcionando sempre como tal. Ele continua sendo, também, pai/mãe, marido/esposa, filho, funcionário, sócio do clube dentre outros. Em cada ambiente, tem um papel identificador ${ }^{3}$.

Com vistas a vislumbrar uma possível via para o enfrentamento do problema levantado nesse estudo, ou seja, a dificuldade da mãe estudante de enfermagem com seus filhos ser modelo de família monoparental, é preciso em primeiro lugar reconhecer que essa situação emerge da atual condição vivida pela mulher moderna em seu contexto social-escolar, onde acreditamos que ambos devem construir o futuro baseado num presente harmônico interativo, que priorize a qualidade de vida. Nessa perspectiva, a educação do futuro necessita promover uma desconstrução dos conhecimentos provenientes das ciências naturais, de modo a reconstruir a condição humana no mundo, a partir dos conhecimentos das ciências humanas, evidenciando a multidimensionalidade e a complexidade humana ${ }^{19}$. 


\section{CONSIDERAÇÕES FINAIS}

Abordar as dificuldades enfrentadas por mulheres, estudantes de enfermagem, que criam seus filhos sem a presença paterna foi um desafio, pelo fato de se tratar de um assunto ainda pouco discutido, e também por elas serem mulheres, mães e estudantes.

Neste estudo, identificou-se em estudantes de enfermagem, que as mães acadêmicas sentem-se angustiadas, estressadas e sobrecarregadas por desempenharem múltiplos papéis no seu cotidiano, todas as entrevistadas consideram o papel de mãe o mais significativo e complexo, por exigir maturidade, estabilidade emocional e responsabilidade com a vida do outro.

Ao optarem pela enfermagem, profissão eminentemente cuidadora, constatei que elas se sentem desamparadas "não cuidadas" dentro do ambiente acadêmico, apesar de os docentes em seus discursos preconizarem o cuidado humanizado do paciente, da família e da comunidade. O cuidado ensinado, não foi percebido e recebido pela mãe acadêmica de Enfermagem.

Acreditamos que o cuidador é um ser que também necessita de cuidados desde o início de sua formação acadêmica, pois o ato de cuidar pode ser aprendido, transmitido e recebido apesar de ser único, particular e singular.

Percebemos que estamos vivendo as conseqüências do modelo feminista, da queima dos sutiãs e tudo o que esta ocorrência representou na vida das mulheres de hoje. As mulheres daquela época deram um passo significativo na busca da evolução feminina no contexto social, determinando uma transformação e revelando zonas de desafios e incertezas sociais. Neste processo, atualmente a mulher se vê criando filhos, trabalhando, cuidando da casa, administrando o orçamento doméstico e, ainda, precisa de tempo para ser mulher.

A partir dos relatos das acadêmicas, identifico ainda que a universidade necessita sofrer adequações para suprir as necessidades de seus alunos, que só poderão ocorrer a partir de uma reforma do pensamento de seus docentes e alunos . Para isso eles devem contribuir na reflexão e construção de uma educação democrática e de qualidade, a fim proporcionar às futuras gerações o direito de repensar o mundo de forma mais responsável e ético.

\section{REFERÊNCIAS}

1 Hironara GMFN. Direito ao pai: dano decorrente de abandono afetivo na relação paterno-filial. Boletim IBDFAM. Belo Horizonte; 2005; (33):3-4.

2 Alves LBM. A constitucionalização do direito de família. Jus Navigandi, Teresina, ${ }^{a} 6$, n.52. Disponível em: <http:// jus2.uol.com.br/doutrina/texto.asp?id> (22 abr.2006).

3 Tiba I. Disciplina, limite na medida certa. São Paulo: Gente; 1996.

4 Woortmann K, Woortmann E. Monoparentalidade e chefia feminina. XIII In: Anais do Encontro Nacional da ABEP; 2002 nov; Ouro Preto (MG); 2002.

5 Abrão IG. A família monoparental formada por mães sozinhas por opção através da utilização de técnicas de inseminação artificial no ordenamento jurídico brasileiro. [monografia]. Belo Horizonte (MG):Pontifícia Universidade Católica de Minas Gerais; 2003.

6 Tiba I. Quem ama, educa! 55. ed. São Paulo: Editora Gente; 2002.

7 Sâmara EM. Mulheres chefes de família no Brasil: séculos XIX e XX. XIII. In: Anais do Encontro Nacional da ABEP; 2002 nov; Ouro Preto (MG); 2002.

8 Thofehrn MB. Vínculos profissionais: uma proposta para o trabalho em equipe na enfermagem. [tese]. Florianópolis (SC): Universidade Federal de Santa Catarina; 2005.

9 Conselho Federal de Enfermagem. Código de Ética dos Profissionais de Enfermagem. Rio de. Janeiro: COFEN; 1993.

10 Ministério da Saúde (BR). Conselho Nacional de Saúde. Resolução n. 196 de 10 de outubro de 1996. Dispõe sobre pesquisa envolvendo seres humanos. Diário Oficial da República Federativa do Brasil Brasília, 10 de out. de 1996.

11 Rocha-Coutinho ML. Tecendo por trás dos panos: a mulher brasileira nas relações familiares. Rio de Janeiro: Rocco; 1994. 
12 Mouly GJ. Psicologia educacional. 7. ed. São Paulo: Pioneira; 1979.

13 Corneu G. Pai ausente filho carente: o que aconteceu com os homens. 2. ed.São Paulo: Brasiliense; 1991. p.45.

14 Boff L. Saber cuidar: Ética do humano - compaixão pela terra. Petrópolis: Vozes; 1999.

15 Campos EP. Quem cuida do cuidador: uma proposta para os profissionais da saúde. Petrópolis: Vozes; 2005.

16 Radünz V. Uma filosofia para enfermeiros: o cuidar de si, a convivência com a finitude e a evitabilidade do burnout. Florianópolis: UFSC; 2001. p.110.
17 Costenaro RGS, Lacerda M R. Quem cuida do cuidador. Santa Maria: Centro Universitário Franciscano; 2001.

18 Moscovici F. Desenvolvimento interpessoal: treinamento em grupo. 4. ed. Rio de Janeiro: José Olympio; 1995.

19 Morin E. Os sete saberes necessários à educação do futuro. 3. ed. São Paulo: Cortez; Brasília: UNESCO; 2001.

20 Freire P. Pedagogia da autonomia: Saberes necessários à prática educativa. 15. ed. São Paulo: Paz e Terra; 1996.

21 Waldow VR. Cuidado humano: o resgate necessário. Porto Alegre: Sagra Luzzatto; 1999. 